elimination is the following. The evacuation of the rectum of its contents is a reflex action which is partly a function of the sacral division of the parasympathetic system. In addition to reflex response produced by local distention of the rectum, involuntary defecation may result from emotional discharges over the sacral nerves (Lindsley, 1951). The role of the sympathetic system, as in many physiological functions other than defecation, is usually the reverse of the parasympathetic. Thus the sympathetic tends to cause retention of contents in the rectum, while the parasympathetic tends to promote evacuation of contents by causing relaxation of the sphincters and contraction and propulsive motility of the rectal walls. The foregoing account suggests that the greater emotional elimination of the MR strain in the open field is associated with a functionally active part of the parasympathetic system, i.e., the sacral division.

Furthermore, the relationship between the autonomic nervous system, in particular the parasympathetic division, and ulceration has long been established (Cushing, 1932). Recently, Francois \& Sines (1961), using an antiserum to a nerve growth protein which selectively reduces the number of cells in the sympathetic chain ganglia of newborn rats, found that the severity of restraint ulceration in rats so treated was greater than in control groups. They interpreted this result as "further support for the notion that parasympathetic dominance is involved in the susceptibility of the rat to immobilization induced stomach lesions." It is known that sympathetic influences are inhibitory to gastric function (Cannon, 1915). Hence, if the sympathetic activity were predominant in the MR rats, ulcer severity would have been lower in this strain. This was not born out by the result of the present study. From what has been cited it may be concluded that (1) the greater emotional elimination of the MR strain appears to reflect greater parasympathetic activity of the sacral division under certain stressful conditions, and that (2) the greater parasympathetic discharge may partly account for the predisposition of the MR strain to ulcer formation.

Follow-up studies wherein the MR and MNR strains were tested for stress-induced ulceration confirmed the findings of the present report. It is worth noting that a comparison of data obtained recently from about 150 Sprague-Dawley and Wistar rats with those of the Maudsley strains indicated clear higher ulcer susceptibility in the MR rats noticeable in both the incidence and character of lesions. Of particular interest in this regard was the location of ulcers. While the ulceration of the Maudsley strains developed mainly in the antrum, no lesions ever appeared in this part of the stomach of Sprague-Dawley and Wistar strains.

\section{REFERENCES}

ADER, R., BEELS, C. C., \& TATUM, R. Blood pepsinogen and gastric erosions in the rat. Psychosomatic Medicine, 1960, 22, 1-12.

BROADHURST, P. L. Experiments in psychogenetics: Applications of biometrical genetics to the inheritance of behavior. In H. J. Eysenck (Ed.), Experiments in personality. Vol. 1. Psychogenetics and psychopharmacology. London: Routledge \& Kegan Paul, 1960. Pp. 1-102.

CANNON, W. B. Bodily changes in pain, hunger, fear and rage. New York: Appleton, 1915.

CUSHING, H. Peptic ulcers and the interbrain. Surgery, Gynecology, and Obstetrics, 1932 $55,1-34$.

EYSENCK, H. J., \& BROADHURST, P. L. Experiments with animals: Introduction. In $\mathrm{H}$ J. Eysenck (Ed.), Experiments in motivation. Oxford: Pergamon Press, 1964. Pp. 285-291.

FRANCOIS, G. R., \& SINES, J. O. Stress induced stomach lesion as related to destruction of the sympathetic ganglia. Journal of Psychosomatic Research, 1961, 5, 191-193.

GELLHORN, E., \& LOOFBOURROW, G. N. Emotions and emotional disorders, a neurophysiological study. New York: Hoeber, 1963. HALL, C. S. Emotional behavior in the rat. I. Defecation and urination as measures of individual differences in emotionality. Journal of Comparative Psychology, 1934, 18, 385-403.

JAY, G. E., JR. Genetic strains and stocks. In W. J. Burdette (Ed.), Methodology in mammalian genetics. San Francisco: Holden-Day, 1963. Pp. 83-126.

LABORATORY ANIMALS CENTRE, Catalogue of uniform strains of laboratory animals maintained in Great Britain. (2nd ed.) London: Laboratory Animals Centre, 1958.

LINDSLEY, D. B. Emotion. In S.S. Stevens (Ed.), Handbook of experimental psychology. New York: Wiley, 1951.
MIKHAIL, A. A. A study of the effects of anxiety on the recovery from gastric ulceration in emotionally reactive strains of rats. Unpublished doctoral dissertation, University of London, 1966.

MIKHAIL, A. A., \& BROADHURST, P. L. Stomach ulceration and emotionality in selected strains of rats. Journal of Psychosomatic Research, 1965, 8, 477-479.

MIKHAIL, A. A., \& HOLLAND, H.C. A simplified method of inducing stomach ulcers. Journal of Psychosomatic Research, 1966a, 9, 343-347.

MIKHAIL, A. A., \& HOLLAND, H. C. Evaluating and photographing experimentally induced stomach ulcers. Journal of Psychosomatic Research, 1966b, 9, 349-353.

SAVAGE, R. D., \& EYSENCK, H. J. Experiments with animals: The definition and measurement of emotionality. In H. J. Eysenck (Ed.) Experiments in motivation. Oxford: Pergamon Press, 1964. Pp. 292-314.

SAWREY, W. L., \& LONG, D. H. Strain and sex differences in ulceration in the rat. Journal of Comparative \& Phy siological Psychology, 1962, 55, 603-605.

SINES, J. O. Selective breeding for development of stomach lesions following stress in the rat. Journal of Comparative \& Physiological Psychology, 1959, 52,615-617.

SINES, J. O. Strain differences in activity, emotionality, body weight and susceptibility to stress induced stomach lesions. Joumal of Genetic Psychology, 1962, 101, 209-216.

SKORYNA, S.C. (Ed.), Pathophysiology of peptic ulcer. Philadelphia: Lippincott, 1963.

\section{NOTES}

1. This study was supported in part by Grant No. APA-197 (07-195-43) from the National Research Council of Canada.

2. Present address: Department of Psychology, University of Manitoba, Winnipeg, Canada.

\title{
Blood pH as a possible hunger cue: Negative evidence'
}

RANDAL D. BEATON, University of
Washington, Seattle, Wash. 98115

An investigation was made into the role of blood $\mathrm{pH}$ in the regulation of food intake. Rats were each subjected to five treatments: acid injection, base injection, two saline injections, and no-injection control. Eating behavior was monitored directly after these treatments. The negative results indicated that blood pH probably does not serve as a hunger cue.

The inability of present theories of hunger regulation to account for all of the available data suggests that perhaps some chemical cue plays a yet undiscovered role in hunger regulation (Smith, 1966). Hydrogen ion concentration of the blood (usually talked of in terms of its $\mathrm{pH}$ or negative logarithmic function) is here investigated as that possible chemical cue.

Upon ingestion of foodstuffs, the parietal cells of the stomach's lining produce a concentrated $\mathrm{HCl}$ secretion which enters the stomach and, at the same time, bicarbonate ions which enter the blood. It has been shown that blood leaving the stomach during gastric secretion is significantly more alkaline than the entering blood, thus accounting for the post-meal "alkaline tide" of blood pH found in humans (Hubbard, 1927) and in dogs (Gyorgy \& Kleinschmidt, 1927).

Thus, while blood $\mathrm{pH}$ and eating do 
Table 1

Amounts of $\mathrm{HCl}$ and $\mathrm{NaHCO}_{3}$ necessary to change blood pH 0.2 acidic and basic respectively with respect to body weight. Calculated from Ruch \& Patton (1965).

Body Weight $\mathrm{HCl}$ Injection $\mathrm{NaHCO}_{3}$ Injection

\begin{tabular}{llr}
$400 \mathrm{~g}$ & $5.45 \mathrm{cc}$ & $9.20 \mathrm{cc}$ \\
$420 \mathrm{~g}$ & $5.72 \mathrm{cc}$ & $9.66 \mathrm{cc}$ \\
$440 \mathrm{~g}$ & $5.99 \mathrm{cc}$ & $10.12 \mathrm{cc}$ \\
$460 \mathrm{~g}$ & $6.25 \mathrm{cc}$ & $10.57 \mathrm{cc}$ \\
$480 \mathrm{~g}$ & $6.51 \mathrm{cc}$ & $11.02 \mathrm{cc}$ \\
$500 \mathrm{~g}$ & $6.78 \mathrm{cc}$ & $11.48 \mathrm{cc}$ \\
\hline
\end{tabular}

covary, apparently no attempt has been made to suggest it as a causal factor in hunger. There are several reasons why a blood pH mechanism may be considered tenable in food intake regulation. It is likely in the regulation of food intake that some blood-borne mechanism is involved and blood pH shifts are of such a direction, magnitude, and time course as to suggest themselves as a possible mechanism. Too, it has been noted that there are centers in the nervous system sensitive to $\mathrm{pH}$ variations. Also of relevance in this regard is the finding that cancer patients show normal appetites as long as they possess the ability to secrete $\mathrm{HCl}$ in their gastric juice, but lose their desire to eat as soon as this ability is lost (Gilmour, 1958). Finally, the finding that exercise leads to a marked increase in the acidity of the blood may be related to the increased ingestion of food that must follow if an energy balance is to be maintained.

The combined implications are that changes in the hydrogen ion concentration of the blood seem at least tenable as a possible satiation and/or hunger cue. The "alkaline tide" after eating would imply a possible satiating effect of lower $\mathrm{H}^{+}$ concentrations while the exercise data would indicate a hunger effect associated with higher $\mathrm{H}^{+}$concentrations. The experimental test of this hypothesis was to independently manipulate blood $\mathrm{pH}$ and note concomitant eating behaviors in rats.

\section{SUBJECTS}

Sixteen large (400-500 g) male Wistar rats, $150-300$ days old, served as Ss. Of these, 10 were used in the data analysis. The reasons for discarding the six unused animals were as follows: two did not eat after the operation, one because of equipment malfunction, and three had their venous catheters come loose.

\section{PROCEDURE}

Subjects were individually housed in Skinner boxes and trained to bar press for 45-mg food pellets on a FR 1:1 schedule. The Ss were then placed on an automated feeding schedule in which the white noise signaled 50-min eating periods twice daily, spaced $12 \mathrm{~h}$ apart. Water was made available at all times. After the response rate was stabilized (about 8 days), they were operated on and a two-way Silastic venous catheter was inserted into the external jugular vein and pushed 1 or $2 \mathrm{~mm}$ into the right atrium of the heart. The other end of the catheter (of PE-50 tubing) was brought around under the skin and exteriorized at the back of the neck so that it protruded about $3 \mathrm{~cm}$. A PVP-heparin mixture was used to fill the catheter when it was not in use to prevent blood from clotting in it. 2

Each $S$ was given a total of five treatments, on five consecutive days. Two of these conditions were acid and base injections. The amounts of osmolar $(.167 \mathrm{M})$ acid $(\mathrm{HCl})$ and osmolar $(.167 \mathrm{M})$ base $\left(\mathrm{NaHCO}_{3}\right)$ that were necessary to change the $\mathrm{pH}$ downward $0.2^{3}$ for the acid injection and upward 0.2 for the base injection according to body weight were calculated (Ruch \& Patton, 1965). (See Table 1.) Since the amounts of base were greater than the amounts of acid required for equivalent but opposite $\mathrm{pH}$ shifts, two isotonic saline control conditions were instituted. One saline injection control matched the amount of $\mathrm{HCl}$ injected and the other matched the amount of $\mathrm{NaHCO}_{3}$ injected. All injection solutions were at body temperature. The fifth and final treatment was a no-injection control condition.

Four days after the operation, the experimental sequence began. Just prior to the normal evening eating period, a $25-\mathrm{cm}$ extension of PE-50 tubing was connected to the cathe ters. Then a .25-cc sample of mixed venous blood was withdrawn into a plastic syringe coated with heparin. In an injection condition the animal received an injection of $\mathrm{HCl}, \mathrm{NaHCO}_{3}$ or saline via a Lambda pump at $.6 \mathrm{ml} / \mathrm{min}$. Thus the injection periods lasted from $9.18 \mathrm{~min}$. After the injection was completed, or after a delay of $5 \mathrm{~min}$ in the no-injection condition, another blood sample was collected as before. At meal time the white noise signal was activated and Ss' evening meal began. The number of bar presses during the next $50 \mathrm{~min}$ was recorded. After this meal another blood sample was collected. The blood samples were stored and cooled and within $1 \mathrm{~h}$ were analyzed for $\mathrm{pH}$ on an Instrumentations Laboratory pH meter. 4

\section{RESULTS AND DISCUSSION}

The averaged blood $\mathrm{pH}$ curves revealed that the shifts due to the acid and base injections were real and close to predicted values: The observed average $\mathrm{pH}$ shifts were 0.25 for acid and 0.23 for base. Variability was slight. In fact, immediately after injection, the $\mathrm{pHs}$ of the animals in the acid and base conditions were entirely out of the range of the control animals' pHs. After $50 \mathrm{~min}$ the $\mathrm{pH}$ shift was still very evident in the base condition but the fact that blood sampling apparently lowers $\mathrm{pH}$ slightly
Table 2

The average number of $45-\mathrm{mg}$ food pellets consumed in relation to experimental condition.

\begin{tabular}{lc}
\hline Condition & $\begin{array}{c}\text { Average Number of } \\
\text { Pellets Ingested }\end{array}$ \\
\hline Acid Injection & 104.1 \\
Base Injection & 93.8 \\
No Injection & 109.2 \\
Saline Control (Acid) & 81.0 \\
Saline Control (Base) & 82.5 \\
\hline
\end{tabular}

obscures the difference in the acid condition. This is probably not crucial since nearly all of the Ss completed their eating within the first $20 \mathrm{~min}$ of the 50 -min eating periods.

The analysis of the eating data was via a 5 by 5 Latin square design independently replicated twice (Edwards, 1960). The analysis revealed no significant differences between any of the treatments $(F=1.252$, $p>.05, \mathrm{df}=4 / 32$ ), thus supplying evidence against any $\mathrm{pH}$ chemical cue in hunger regulation. It is possible to argue that the acid and base injections made the animals sick and unable to eat normally, but the eating data revealed that animals in the no-injection and saline conditions did not eat significantly more food (see Table 2). It thus seems that rats are able to regulate their food intake in spite of slight variations in blood $\mathrm{pH}$ rather than because of them.

\section{REFERENCES}

EDWARDS, A. Experimental design in psycho logical research. New York: Holt, Rinehart \& Winston, 1960 .

GILMOUR, J. Clinical aspect of carcinoma of stomach in diagnosis. British Medical Joumal, 1958, 5073, 745-748.

GYORGY, P., \& KLEINSCHMIDT. Experiments on dogs with the London angiostomy. Zeitschrift fùr gesamte und experimentelle Medizin, 1927, 54(1/2), 23-31.

HUBBARD, R. The effect of a meal upon the titratable alkalinity of the blood. Proceedings of the Society for Experimental Biology \& Medicine, 1927, 25(1), 71-72.

RUCH, T. \& PATTON, H. Physiology and biophysics. Philadelphia: Saunders Co., 1965. SMITH, M. Effect of hypertonic preloads on concurrent eating and drinking. Journal of Comparative \& Phy siological Psy chology, 1966, 61, 398-401.

\section{NOTES}

1. Supported by PHS Grants 5T01GM00666-08 and $\mathrm{MH} \mathrm{11148-04}$. I would like to express my thanks to the following people for their help Moncrieff Smith, Steven Woods, Garvin Holman and David Kostansek, who all made sizable contributions to both the research and to the writing of the manuscript.

2. Technique developed by J. D. Davis

3. This $\mathrm{pH}$ shift is somewhat greater than a $\mathrm{pH}$ shift due to eating but of a magnitude comparable to that developed in strenuous exercise. A pH shift of this magnitude was selected to keep the shifts equal. While the shifts are sizable they are merely at the extremes of the normal range and do not cause a noticeable sickness. In addition, pilot work revealed that $\mathrm{pH}$ shifts of this size could be maintained for $1 \mathrm{~h}$.

4. Made available through the courtesy of Children's Orthopedic Hospital, Seattle, Washing. ton. 